\title{
Discontinuation of low dose aspirin and risk of myocardial infarction: case-control study in UK primary care
}

\author{
Luis A García Rodríguez director ${ }^{1}$, Lucía Cea-Soriano epidemiologist ${ }^{1}$, Elisa Martín-Merino \\ epidemiologist ${ }^{1}$, Saga Johansson senior principal scientist/associate professor $^{23}$
}

${ }^{1}$ Spanish Centre for Pharmacoepidemiologic Research (CEIFE), Madrid 28004, Spain; ${ }^{2}$ AstraZeneca Research and Development, Mölndal, Sweden; ${ }^{3}$ Institute of Medicine, Sahlgrenska Academy, Gothenburg University, Gothenburg, Sweden

\begin{abstract}
Objectives To evaluate the risk of myocardial infarction and death from coronary heart disease after discontinuation of low dose aspirin in primary care patients with a history of cardiovascular events.

Design Nested case-control study.

Setting The Health Improvement Network (THIN) database in the United Kingdom.

Participants Individuals aged 50-84 with a first prescription for aspirin (75-300 mg/day) for secondary prevention of cardiovascular outcomes in 2000-7 ( $n=39$ 513).
\end{abstract}

Main outcome measures Individuals were followed up for a mean of 3.2 years to identify cases of non-fatal myocardial infarction or death from coronary heart disease. A nested case-control analysis assessed the risk of these events in those who had stopped taking low dose aspirin compared with those who had continued treatment.

Results There were 876 non-fatal myocardial infarctions and 346 deaths from coronary heart disease. Compared with current users, people who had recently stopped taking aspirin had a significantly increased risk of non-fatal myocardial infarction or death from coronary heart disease combined (rate ratio $1.43,95 \%$ confidence interval 1.12 to 1.84 ) and non-fatal myocardial infarction alone (1.63, 1.23 to 2.14$)$. There was no significant association between recently stopping low dose aspirin and the risk of death from coronary heart disease $(1.07,0.67$ to 1.69$)$. For every 1000 patients, over a period of one year there were about four more cases of non-fatal myocardial infarction among patients who discontinued treatment with low dose aspirin (recent discontinuers) compared with patients who continued treatment.

Conclusions Individuals with a history of cardiovascular events who stop taking low dose aspirin are at increased risk of non-fatal myocardial infarction compared with those who continue treatment.

\section{Introduction}

Low dose regimens of the antiplatelet agent aspirin (acetylsalicylic acid) are a standard treatment for the secondary prevention of cardiovascular outcomes. Meta-analysis of randomised controlled trials has shown that low dose aspirin is protective in most types of patient at increased risk of occlusive vascular events, including those who have had an acute myocardial infarction or ischaemic stroke and those who have stable or unstable angina, peripheral artery disease, or atrial fibrillation. ${ }^{1}$ Guidelines recommend long term use of low dose aspirin $(75-150 \mathrm{mg} / \mathrm{day})$ as an effective antiplatelet regimen for patients with cardiovascular disease, unless contraindicated. ${ }^{2}{ }^{3}$ Despite the strong evidence supporting the protective effects of low dose aspirin, discontinuation rates of around $50 \%$ have been reported in patients who have been taking this medication for several years. ${ }^{45}$ It is therefore of concern that recent discontinuation has been linked to an increase in the risk of ischaemic events and death. Cessation of treatment with oral antiplatelet agents (including aspirin and thienopyridines) has been shown to be an independent predictor of an increase in mortality after acute coronary syndromes, ${ }^{6}$ and multivariate analysis has shown an increased risk of transient ischaemic attack in the four weeks after discontinuation of aspirin. ${ }^{7}$ Another study of a cohort of patients with acute coronary syndromes found that acute coronary syndrome events occurred on average 10 days after discontinuation of low dose aspirin. ${ }^{8}$ A systematic review of the literature to date showed that withdrawal of low dose aspirin is associated with a threefold increase in the risk of adverse cardiovascular events.'

All the studies on this topic to date, however, have taken place in secondary care centres. We used a validated primary care database to evaluate the risk of non-fatal myocardial infarction and of death from coronary heart disease (both as separate end points and as a combined measure) after discontinuation of low 
dose aspirin in primary care patients taking it as secondary prevention for cardiovascular disease.

\section{Methods \\ Data source}

The Health Improvement Network is a computerised medical research database that contains systematically recorded data on more than three million patients enrolled in primary care practices in the United Kingdom. Almost all of the UK population is registered with a primary care practitioner, and the network is representative of the UK population with regard to age, sex, and geographical distribution. It has also been validated for use in pharmacoepidemiological research. ${ }^{10}$ Participating primary care practitioners record data as part of their routine care of patients, including demographic factors, consultation rates, referrals, hospital admissions, results of laboratory tests, diagnoses, and prescriptions written, and send them to the network for use in research projects. The Read classification is used to code specific diagnoses, ${ }^{11}$ and a drug dictionary based on data from the MULTILEX classification is used to code drug prescriptions. ${ }^{12}$

Studies have shown that $60-80 \%$ of UK patients who take aspirin for secondary prevention obtain their treatment by prescription rather than over the counter. ${ }^{13-15}$ This proportion increases with age $^{13}$ and in those patients who do not have to pay prescription charges. ${ }^{15}$ The Health Improvement Network should therefore be a representative source of data on low dose aspirin use in the UK.

\section{Source population}

We used the network to identify individuals aged 50-84 with a first ever prescription of low dose aspirin (defined as 75-300 $\mathrm{mg}$ /day) for the secondary prevention of cardiovascular or cerebrovascular events (defined as a diagnosis of angina (including stable angina), unstable angina, ischaemic heart disease, myocardial infarction, cerebrovascular disease, stroke, or transient ischaemic attack) from 1 January 2000 to 31 December 2007 (figure). Indications for first ever prescriptions for low dose aspirin were identified from the patients' computerised records. This was done manually when there was more than one potential indication. Study participants were required to have been registered with their primary care practitioner for at least two years and to have a computerised prescription history for at least a year before the start of the study. They were also required to have no diagnosis of cancer, alcohol abuse, or alcohol related disease.

All individuals in the study cohort were followed up from the day after their first prescription of low dose aspirin (start date) until the first of the following end points: first recorded diagnosis of myocardial infarction, cancer, alcohol abuse, age 85, death, or the end of the study period (31 December 2007). The final study cohort of 39513 patients was followed up for a mean of 3.2 years (range 1.0 day to 8.0 years, SD 2.2 ).

\section{Selection of cases and case validation}

During follow-up, 3155 patients in the study cohort had a recorded diagnosis of myocardial infarction (figure). We manually reviewed the profiles of these patients, including the free text comments, to ascertain the number of patients with a new diagnosis of myocardial infarction or who died from coronary heart disease. We excluded patients with myocardial infarction if they were not admitted to hospital after the ischaemic event (and patients who were admitted to an emergency department and discharged on the same day) because events that do not require admission have lower diagnostic value than those that do require admission, which results in greater misclassification. Patients were also excluded if they were admitted to hospital for any reason other than cardiovascular disease and had a myocardial infarction while admitted.

There were 2869 recorded deaths during the follow-up, and 824 of these patients had a recorded cardiovascular diagnosis in the 30 days before death (figure). We manually reviewed the profiles of these 824 individuals to identify those who had died from coronary heart disease. All those with coronary heart disease recorded on their death certificate as the underlying cause of death, or who had had a recent coronary artery occlusion or antemortem evidence of coronary heart disease in the absence of another cause of death, were considered to have died from coronary heart disease. All other patients were excluded.

Previous studies have found that validation of diagnoses of myocardial infarction by a primary care practitioner and records of death from coronary heart disease results in a confirmation rate of more than $90 \%,{ }^{16}{ }^{17}$ so we did not carry out further validation with primary care practitioners in our study.

After the complete review process of patients with a diagnosis of myocardial infarction and patients who had potentially died from coronary heart disease, we classified 876 individuals as having non-fatal myocardial infarction and 346 individuals as having died from coronary heart disease (including fatal myocardial infarction) (figure).

\section{Selection of controls}

From the same source population of 39513 patients, we randomly sampled a control group of 5000 individuals, frequency matched to the cases by age, sex, and calendar year. We used incidence density sampling so that the likelihood of being selected as a control was proportional to the person time at risk. To do this, we generated a date at random during the study period for each of the members of the source population. We obtained the random date with a pseudo-random number generator included in the $\mathrm{C}++$ standard library. If the random date of a study member was included in his or her eligible person time, we used his or her random date as the index date and marked that person as an eligible control.

\section{Assessment of risk factors}

From the database we collected data on potential risk factors, including the number of visits to a primary care practitioner, referrals, and admissions to hospital (the year before the index date), lifestyle factors (any time before the index date), morbidities (any time before the start date), and drug treatment (between the start date and the index date). Drug treatment other than low dose aspirin was classified into four categories:

- current use-when the supply of the most recent prescription lasted until the index date or ended in the six days before the index date

- recent use-when the supply of the most recent prescription ended seven to 90 days before the index date (for all medications, except warfarin, for which recent use was defined as seven to 365 days before the index date)

- past use-when the most recent prescription ended 91 to 365 days before the index date

- non-use-when there was no recorded use of the relevant drug in the 365 days before the index date. 
We chose six days as the cut off for current use to allow for patients who did not completely adhere to their treatment and might still have been using the drug after the specified completion date.

\section{Assessment of discontinuation of low dose aspirin}

Current users were defined as individuals who were taking low dose aspirin at the index date, and discontinuers were defined as individuals with a period of over 30 days after the last prescription would have been finished (assuming complete adherence) who did not refill their prescription during this time. Discontinuers were then categorised into two mutually exclusive groups:

- recent discontinuers were patients whose last prescription for low dose aspirin finished 31 to 180 days before the index date

- distant discontinuers were those whose last prescription finished 181 to 365 days before the index date.

To assess the effect of the definition of discontinuation, we performed a second analysis with discontinuation defined as a period of over 15 days after the last prescription would have been finished (assuming complete adherence), with no refill of the prescription during this time. In each case, investigators were blinded as to whether the record belonged to a case or a control.

We identified reasons for discontinuation through manual review of patients' profiles and classified them into four mutually exclusive categories:

- treatment change-defined as a switch, initiated by a physician, from low dose aspirin to another antiplatelet drug (such as clopidogrel or dipyridamole) or to an anticoagulant such as warfarin, with no evidence to suggest an adverse event related to aspirin

- safety concerns-defined as evidence of an adverse event related to low dose aspirin treatment (such as upper gastrointestinal bleeding or other upper gastrointestinal complications), intolerance to low dose aspirin (allergy/urticaria), initiation of gastroprotective medication, or planned surgery

- use of over the counter aspirin-reported when the general practitioner specified that patients were taking low dose aspirin in the absence of a recorded prescription for aspirin

- non-adherence - defined as discontinuation in the absence of any of the above factors.

\section{Analysis}

We calculated the incidence of non-fatal myocardial infarction and of death from coronary heart disease and performed a nested case-control analysis using unconditional logistic regression to assess potential risk factors for these outcomes. ${ }^{18}$ The logistic regression was used to estimate odds ratios, which are unbiased estimates of incidence rate ratios in incidence density sampling. ${ }^{19}$

The analyses used the occurrence of myocardial infarction and death from coronary heart disease as the dependent variable and the factors listed below as independent variables. Missing demographic data were assessed as a separate category. Risk estimates were adjusted by age, sex, calendar year, time to event, smoking status, ischaemic heart disease (at start date), cerebrovascular disease (at start date), diabetes (at start date), chronic obstructive pulmonary disease (at start date), and use of clopidogrel, statins, anticoagulants, nitrates, antihypertensives, oral steroids, or non-steroidal anti-inflammatory drugs. Analyses were stratified by sex and age. The significance of the interaction was tested with a likelihood test ratio by comparing a model with the main effect of two variables (sex and discontinuation) and the interaction term with a reduced model incorporating only the main effects. We also performed sensitivity analyses to assess the risk of residual confounding.

\section{Results}

\section{Incidence of non-fatal myocardial infarction and death from coronary heart disease}

Over a mean follow-up of 3.2 years, we identified 876 individuals with a new diagnosis of non-fatal myocardial infarction (figure). In addition, we identified 346 individuals as having died from coronary heart disease. The overall incidence of non-fatal myocardial infarction was 6.87 per 1000 person years (95\% confidence interval 6.43 to 7.34 ). The overall incidence of death from coronary heart disease was 2.71 per 1000 person years (2.44 to 3.02). The incidence of these outcomes stratified by indication for low dose aspirin is shown in table B in the appendix on bmj.com.

The combined incidence of non-fatal myocardial infarction or death from coronary heart disease was 9.58 per 1000 person years (9.06 to 10.14). This was higher in the first year of follow-up (12.92 per 1000 person years, 11.78 to 14.17) than in the rest of the study period $(8.33,7.76$ to 8.94$)$.

\section{Risk factors for non-fatal myocardial infarction and death from coronary heart disease}

Several baseline characteristics and lifestyle factors were associated with a significantly increased risk of non-fatal myocardial infarction or death from coronary heart disease in users of low dose aspirin (table 1). Current smokers had a significantly increased risk of non-fatal myocardial infarction or death from coronary heart disease compared with non-smokers, and patients who had been admitted to hospital in the year before the index date had a significantly greater risk than those who had not been admitted in that time. Compared with no diagnosis of the respective disease, a previous diagnosis of chronic obstructive pulmonary disease or diabetes was also associated with a significant increase in the risk of non-fatal myocardial infarction or death from coronary heart disease in this cohort of patients taking low dose aspirin (table 1).

Concomitant use of oral steroids (rate ratio $2.32,95 \%$ confidence interval 1.65 to 3.26 ) and traditional non-steroidal anti-inflammatory drugs $(1.36,1.04$ to 1.77$)$ was associated with a significant increase in the risk of non-fatal myocardial infarction or death from coronary heart disease compared with non-use. In contrast, patients currently taking statins had a significant decrease in risk compared with non-users $(0.82,0.69$ to 0.97$)$.

\section{Discontinuation of low dose aspirin and cardiovascular outcomes}

Among the 1222 cases, 877 (72\%) were still using low dose aspirin, $108(9 \%)$ were recent discontinuers, and 41 (3\%) were distant discontinuers. Among the 5000 controls, 3784 (76\%) were still using low dose aspirin, 357 (7\%) were recent discontinuers, and 195 (4\%) were distant discontinuers. Most recent discontinuers were non-adherent (68\% of all recent discontinuers). Twelve per cent of patients switched to another 
antiplatelet or anticoagulant medication and $6 \%$ were using over the counter low dose aspirin.

Individuals who had recently discontinued low dose aspirin had a significantly increased risk of non-fatal myocardial infarction or death from coronary heart disease compared with current users (rate ratio 1.43, 1.12 to 1.84; table 2). This increased risk among recent discontinuers was similar for different durations of treatment with aspirin (table 2), and for the different indications (data not shown). There was no significant association between distant discontinuation of low dose aspirin and the risk of non-fatal myocardial infarction or death from coronary heart disease $(1.19,0.82$ to 1.71$)$ compared with current low dose aspirin use. There was also no significant difference in risk in distant discontinuers compared with recent discontinuers (data not shown). The increase in risk was virtually unchanged when we changed the definition of recent

discontinuation to a period of more than 15 days after the end of the last prescription for low dose aspirin (1.41, 1.12 to 1.76). The risk estimate was also similar when we further adjusted the multivariate model by the number of admissions to hospital in the year before the index date (1.46, 1.14 to 1.87$)$.

When we categorised recent discontinuers according to their reason for discontinuation, there was a significant increase in the risk of myocardial infarction or death from coronary heart disease in those who were non-adherent (rate ratio 1.54 (1.15 to 2.06) compared with current use), but not in those who were defined as discontinuers but who were subsequently found to be taking over the counter low dose aspirin (rate ratio $0.82(0.28$ to 2.38) compared with current use).

Recent discontinuers of low dose aspirin had a significantly increased risk of non-fatal myocardial infarction compared with current users (rate ratio 1.63, 1.23 to 2.14; table 3 ). Based on an incidence of non-fatal myocardial infarction of about six per 1000 person years among current users of low dose aspirin, the incidence among recent discontinuers can be estimated as 10 per 1000 patient years: an extra four cases of non-fatal myocardial infarction associated with discontinuation among 1000 aspirin users. The risk of non-fatal myocardial infarction was significantly increased in patients who did not adhere to treatment but not in those who were taking over the counter low dose aspirin (table 3). The risk of non-fatal myocardial infarction in recent discontinuers varied slightly across the different age groups (table 3 ). The risk was higher in women than in men, but this difference was not significant ( $\mathrm{P}=0.16$ for interaction).

There was no significant association between discontinuation of low dose aspirin treatment and death from coronary heart disease among recent discontinuers (rate ratio $1.07,0.67$ to 1.69 ) or distant discontinuers $(1.02,0.54$ to 1.94$)$ compared with current users. There was also no significant increase in the risk of death from coronary heart disease when recent discontinuers were restricted to those who were truly non-adherent (rate ratio $1.03,0.59$ to 1.79 ).

The risk of myocardial infarction or death from coronary heart disease seemed to be unaffected by adherence to other medications. For example, the risk in patients who discontinued low dose aspirin but were adherent to antihypertensive drugs (rate ratio 1.54, 1.00 to 2.38) was similar to that in the overall cohort. Similarly, there was no significant increase in the risk in patients who discontinued other drugs (see table $\mathrm{C}$ in appendix on bmj.com). Sensitivity analyses showed the association between discontinuing low dose aspirin and the risk of myocardial infarction or death from coronary heart disease to be robust. For the increased risk of coronary events among recent discontinuers to become non-significant, the analysis would have to be adjusted by an unknown confounder with an overall prevalence of $25 \%$ that is twice as common among discontinuers than non-discontinuers and a major risk factor for coronary events (rate ratio of $\geq 3$ ).

\section{Discussion}

Patients with a history of cardiovascular or cerebrovascular disease in primary care who stop taking low dose aspirin are at a significantly increased risk of non-fatal myocardial infarction compared with those who continue such treatment. The increased risk is present irrespective of the length of time the patient had previously been taking low dose aspirin. This supports the results of previous studies in secondary care ${ }^{68}$ and shows that they are applicable to the general population. An additional important finding is that the cumulative incidence of non-fatal myocardial infarction or death from coronary heart disease in patients taking low dose aspirin after a myocardial infarction was $4 \%$ during the mean follow-up of three years. This is consistent with data from clinical trials on the effectiveness of antithrombotic treatment for the secondary prevention of cardiovascular events, which indicate that 2-14\% of patients (followed for a mean of 1 to 41 months) have a subsequent ischaemic event. ${ }^{20-23}$

\section{Strengths and weaknesses}

A major strength of this study is that use of The Health Improvement Network enabled analysis of an extensive sample that was representative of the UK primary care population and had age and sex distributions similar to those in the national population. Also, the network includes all patients in participating practices who have been diagnosed as having a primary cardiovascular event and prescribed low dose aspirin to prevent a secondary event in primary care, supporting the broad external validity of these findings. Moreover, we observed the increased risk of non-fatal myocardial infarction in patients who were truly non-adherent but not in those who were found to be taking over the counter aspirin, which reinforces the internal validity of this study.

A potential limitation of the study is that use of aspirin might have been misclassified in some cases. For example, the recording of a prescription for low dose aspirin in The Health Improvement Network does not necessarily mean that the patient actually took it, although it is likely that many did as there was a prescription almost every month for most patients. Lack of systematic recording of over the counter aspirin is another potential source of misclassification. As described above, however, in the age range studied use of low dose aspirin for secondary prevention is predominantly prescription based. ${ }^{13} 15$ Another limitation is the potential for confounding, which is a limitation of all observational studies. We have tried to control for this as much as possible by adjusting the multivariate analyses by demographic factors, traditional cardiovascular risk factors, comorbidity, and drug use. Nevertheless, it is not possible to control for all possible confounding factors, and it should be acknowledged that some of these factors might have had an impact on aspirin discontinuation rates. Sensitivity analyses showed that the association between discontinuation and the risk of myocardial infarction or death from coronary heart disease was robust. We think that it would therefore be unlikely for the association to be explained by unmeasured confounding. 


\section{Conclusions and clinical implications}

We have shown that discontinuation of low dose aspirin increases the risk of non-fatal myocardial infarction in patients with a history of ischaemic events in primary care. The magnitude of this short term increase in risk after discontinuation is about the inverse of the benefit obtained with use of low dose aspirin treatment for secondary prevention. The implications of interrupting such treatment should be taken into account when managing the secondary prevention of cardiovascular events in primary care.

Non-adherence in patients was the most common reason for discontinuation of low dose aspirin. Additional research is required to determine why patients stop this treatment in the absence of a clinical reason. Patients might not adhere to treatment because they forget to take it, because they do not perceive that it has therapeutic benefit, or because of adverse events not discussed with their primary care practitioner. Recorded safety concerns were the second most common reason for discontinuation in this study. Upper gastrointestinal side effects, including peptic ulcer disease and bleeding, ${ }^{24}{ }^{25}$ are the most serious adverse effects related to aspirin use. ${ }^{26}$ Low dose aspirin, however, is of substantial net benefit in secondary prevention because the reduction in the risk of major coronary events outweighs the increased risk of major gastrointestinal bleeding in patients at high risk of cardiovascular events. ${ }^{122} 2327$ Reducing the number of patients who discontinue low dose aspirin could therefore have a major impact on the benefit obtained with low dose aspirin in the general population. Research is now needed to evaluate whether efforts to encourage patients to continue prophylactic treatment with low dose aspirin will result in a decrease in non-fatal myocardial infarction.

We thank Nesta Hughes and Catherine Hill, of Oxford PharmaGenesis, who provided writing support funded by AstraZeneca.

Contributors: LAGR contributed to study design, data collection, statistical analysis, interpretation of data, and drafting the report; LC-S and EM-M contributed to data collection and statistical analysis and reviewed the report; $\mathrm{S} J$ contributed to study design, interpretation of data, and reviewed the report. LAGR is guarantor.

Funding: This study was funded by an unrestricted research grant from AstraZeneca Research and Development Mölndal. The sponsors played no part in the design or conduct of the study.

Competing interests: All authors have completed the Unified Competing Interest form at www.icmje.org/coi_disclosure.pdf (available on request from the corresponding author); LAGR, LC-S and EM-M work for CEIFE, which has received research funding from AstraZeneca; $\mathrm{SJ}$ is an employee of AstraZeneca.

Ethical approval: This study was approved by the multicentre research ethics committee (08/H0305/49).

Data sharing: No additional data available.
1 Antithrombotic Trialists' Collaboration. Collaborative meta-analysis of randomised trials of antiplatelet therapy for prevention of death, myocardial infarction, and stroke in high risk patients. BMJ 2002;324:71-86.

2 Smith SC Jr, Allen J, Blair SN, Bonow RO, Brass LM, Fonarow GC, et al. AHA/ACC guidelines for secondary prevention for patients with coronary and other atherosclerotic vascular disease: 2006 update endorsed by the National Heart, Lung, and Blood Institute. J Am Coll Cardiol 2006;47:2130-9.

3 Graham I, Atar D, Borch-Johnsen K, Boysen G, Burell G, Cifkova R, et al. European guidelines on cardiovascular disease prevention in clinical practice: executive summary. Eur Heart $J$ 2007;28:2375-414.

4 Sud A, Kline-Rogers EM, Eagle KA, Fang J, Armstrong DF, Rangarajan K, et al. Adherence to medications by patients after acute coronary syndromes. Ann Pharmacother 2005;39:1792-7.

5 García Rodríguez LA, Cea Soriano L, Martín-Merino E, Johansson S. Discontinuation of low-dose acetylsalicylic acid treatment for secondary prevention of cardiovascular outcomes. Circulation 2009;120:S480.

6 Collet JP, Montalescot G, Blanchet B, Tanguy ML, Golmard JL, Choussat R, et al. Impact of prior use or recent withdrawal of oral antiplatelet agents on acute coronary syndromes. Circulation 2004;110:2361-7.

7 Maulaz AB, Bezerra DC, Michel P, Bogousslavsky J. Effect of discontinuing aspirin therapy on the risk of brain ischemic stroke. Arch Neurol 2005;62:1217-20.

8 Ferrari E, Benhamou M, Cerboni P, Marcel B. Coronary syndromes following aspirin withdrawal: a special risk for late stent thrombosis. J Am Coll Cardiol 2005;45:456-9.

9 Biondi-Zoccai GG, Lotrionte M, Agostoni P, Abbate A, Fusaro M, Burzotta F, et al. A systematic review and meta-analysis on the hazards of discontinuing or not adhering to aspirin among 50,279 patients at risk for coronary artery disease. Eur Heart $J$ 2006;27:2667-74.

10 Lewis JD, Schinnar R, Bilker WB, Wang X, Strom BL. Validation studies of the health improvement network (THIN) database for pharmacoepidemiology research. Pharmacoepidemiol Drug Saf 2007;16:393-401.

11 Stuart-Buttle CD, Read JD, Sanderson HF, Sutton YM. A language of health in action Read Codes, classifications and groupings. Proc AMIA Annu Fall Symp 1996:75-9.

12 First Data Bank. MULTILEX for primary care. 2010. www.firstdatabank.co.uk/uploads/ files/MultilexDDF\%20for\%20Primary\%20Care.pdf.

13 Bedson J, Whitehurst T, Lewis M, Croft P. Factors affecting over-the-counter use of aspirin in the secondary prophylaxis of cardiovascular disease. Br J Gen Pract 2001;51:1001-3.

14 Campbell NC, Thain J, Deans HG, Ritchie LD, Rawles JM. Secondary prevention in coronary heart disease: baseline survey of provision in general practice. $B M J$ 1998:316:1430-4.

15 Hopper S, Pierce M. Aspirin after myocardial infarction: the importance of over-the-counter use. Fam Pract 1998;15(suppl 1):S10-3

16 García Rodríguez LA, Tacconelli S, Patrignani P. Role of dose potency in the prediction of risk of myocardial infarction associated with nonsteroidal anti-inflammatory drugs in the general population. J Am Coll Cardiol 2008;52:1628-36.

17 García Rodríguez LA, Varas-Lorenzo C, Maguire A, Gonzalez-Perez A. Nonsteroidal antiinflammatory drugs and the risk of myocardial infarction in the general population. Circulation 2004;109:3000-6.

18 Rothman KJ, Greenland S. Modern epidemiology. Lippincott-Raven, 1998.

19 Pearce N. What does the odds ratio estimate in a case-control study? Int $J$ Epidemiol 1993;22:1189-92.

20 Newby LK. Randomized trial of aspirin, sibrafiban, or both for secondary prevention after acute coronary syndromes. Circulation 2001;103:1727-33.

21 Krol WF. The Persantine-Aspirin Reinfarction Study Research Group. Persantine and aspirin in coronary heart disease. Circulation 1980;62:449-61.

22 Baigent C, Blackwell L, Collins R, Emberson J, Godwin J, Peto R, et al. Aspirin in the primary and secondary prevention of vascular disease: collaborative meta-analysis of individual participant data from randomised trials. Lancet 2009;373:1849-60.

23 Antiplatelet Trialists' Collaboration. Collaborative overview of randomised trials of antiplatelet therapy - I: Prevention of death, myocardial infarction, and stroke by prolonged antiplatelet therapy in various categories of patients. BMJ 1994;308:81-106.

24 Slattery J, Warlow CP, Shorrock CJ, Langman MJ. Risks of gastrointestinal bleeding during secondary prevention of vascular events with aspirin-analysis of gastrointestinal bleeding during the UK-TIA trial. Gut 1995;37:509-11.

$25 \mathrm{Ng} \mathrm{W}$, Wong WM, Chen WH, Tse HF, Lee PY, Lai KC, et al. Incidence and predictors of upper gastrointestinal bleeding in patients receiving low-dose aspirin for secondary prevention of cardiovascular events in patients with coronary artery disease. World $J$ Gastroenterol 2006;12:2923-7.

26 Lanas A, Scheiman J. Low-dose aspirin and upper gastrointestinal damage: epidemiology, prevention and treatment. Curr Med Res Opin 2007;23:163-73.

27 Björklund L, Wallander MA, Johansson S, Lesén E. Aspirin in cardiology-benefits and risks. Int J Clin Pract 2009;63:468-77.

Accepted: 13 May 2011

Cite this as: BMJ 2011;343:d4094 


\section{What is already known on this topic}

Low dose aspirin is standard treatment for the secondary prevention of cardiovascular disease, though up to half of long term users stop taking it

Secondary care studies have shown that discontinuation is associated with an increased risk of ischaemic events and death

\section{What this study adds}

Discontinuation of low dose aspirin increases the risk of non-fatal myocardial infarction or death from coronary heart disease by almost $50 \%$ in patients in primary care who have a history of ischaemic events

There is no increase in the risk of death from coronary heart disease alone in patients who discontinue low dose aspirin The increased risk of non-fatal myocardial infarction after discontinuation is present irrespective of the length of time the patient had previously been taking low dose aspirin.

Research is now needed to test whether efforts to encourage patients to continue prophylactic treatment with low dose aspirin result in a decrease in non-fatal myocardial infarction

\section{Tables}

Table 1| Rate ratios for combined non-fatal myocardial infarction (MI) or death from coronary heart disease (CHD) associated with various factors in patients taking low dose aspirin

\begin{tabular}{|c|c|c|c|c|}
\hline \multirow[b]{2}{*}{ Factor } & \multirow[b]{2}{*}{ No $(\%)$ of controls $(n=5000)$} & \multirow{2}{*}{$\begin{array}{l}\text { No (\%) with non-fatal } \\
\text { MI/CHD death }(n=1222)\end{array}$} & \multicolumn{2}{|c|}{ Rate ratio $(95 \% \mathrm{Cl})$} \\
\hline & & & Unadjusted $^{*}$ & Adjustedt \\
\hline \multicolumn{5}{|l|}{ Smoking: } \\
\hline Never & $2014(40.3)$ & $404(33.1)$ & 1.00 & 1.00 \\
\hline Current & $724(14.5)$ & $259(21.2)$ & 1.86 (1.55 to 2.23$)$ & 1.67 (1.38 to 2.03$)$ \\
\hline Former & $2135(42.7)$ & $527(43.1)$ & $1.28(1.10$ to 1.48$)$ & 1.15 (0.98 to 1.35$)$ \\
\hline Unknown & $127(2.5)$ & $32(2.6)$ & $1.08(0.72$ to 1.63$)$ & $1.26(0.82$ to 1.91$)$ \\
\hline \multicolumn{5}{|l|}{ BMI: } \\
\hline $15-19$ & $133(2.7)$ & $35(2.9)$ & $1.16(0.78$ to 1.73$)$ & 1.04 (0.69 to 1.58$)$ \\
\hline $20-24$ & $1316(26.3)$ & $304(24.9)$ & 1.00 & 1.00 \\
\hline $25-29$ & $1934(38.7)$ & $469(38.4)$ & $1.06(0.90$ to 1.24$)$ & $1.10(0.93$ to 1.31$)$ \\
\hline $30-59$ & $1119(22.4)$ & $284(23.2)$ & $1.16(0.96$ to 1.39$)$ & $1.10(0.91$ to 1.34$)$ \\
\hline Unknown & $498(10.0)$ & $130(10.6)$ & $1.07(0.85$ to 1.35$)$ & $1.13(0.87$ to 1.46$)$ \\
\hline \multicolumn{5}{|c|}{ Visits to primary care practitionerł: } \\
\hline$<5$ & $441(8.8)$ & $86(7.0)$ & 1.00 & 1.00 \\
\hline $5-9$ & $1356(27.1)$ & $255(20.9)$ & $1.02(0.78$ to 1.33$)$ & $0.98(0.74$ to 1.30$)$ \\
\hline $10-19$ & $2147(42.9)$ & $518(42.4)$ & 1.35 (1.05 to 1.74$)$ & 1.16 (0.89 to 1.53$)$ \\
\hline$\geq 20$ & $1056(21.1)$ & $363(29.7)$ & 1.96 (1.50 to 2.55$)$ & 1.49 (1.11 to 2.00$)$ \\
\hline \multicolumn{5}{|l|}{ Referralsł: } \\
\hline $0-1$ & $2391(47.8)$ & $472(38.6)$ & 1.00 & 1.00 \\
\hline $2-4$ & $1476(29.5)$ & $379(31.0)$ & 1.34 (1.15 to 1.56$)$ & 1.22 (1.04 to 1.44 ) \\
\hline $5-9$ & $812(16.2)$ & $249(20.4)$ & 1.65 (1.39 to 1.97$)$ & 1.39 (1.15 to 1.68$)$ \\
\hline$\geq 10$ & $321(6.4)$ & $122(10.0)$ & 2.10 (1.66 to 2.66$)$ & 1.71 (1.32 to 2.20$)$ \\
\hline \multicolumn{5}{|l|}{ Admission to hospitalł: } \\
\hline 0 & $4133(82.7)$ & $834(68.3)$ & 1.00 & 1.00 \\
\hline $1-2$ & $721(14.4)$ & $309(25.3)$ & 2.11 (1.81 to 2.46$)$ & 1.76 (1.49 to 2.08 ) \\
\hline$\geq 3$ & $146(2.9)$ & $79(6.5)$ & 2.74 (2.06 to 3.65 ) & 2.06 (1.50 to 2.83 ) \\
\hline \multicolumn{5}{|l|}{ Morbidity at start date§: } \\
\hline Myocardial infarction & $1160(23.2)$ & $450(36.8)$ & 1.95 (1.70 to 2.23$)$ & 1.91 (1.61 to 2.55$)$ \\
\hline Angina & $1790(35.8)$ & $491(40.2)$ & 1.19 (1.04 to 1.35$)$ & $1.10(0.93$ to 1.30$)$ \\
\hline Unstable angina & $162(3.2)$ & $66(5.4)$ & 1.69 (1.26 to 2.27$)$ & 1.43 (1.04 to 1.96$)$ \\
\hline
\end{tabular}


Table 1 (continued)

\begin{tabular}{|c|c|c|c|c|}
\hline \multirow[b]{2}{*}{ Factor } & \multirow[b]{2}{*}{ No $(\%)$ of controls $(n=5000)$} & \multirow{2}{*}{$\begin{array}{l}\text { No (\%) with non-fatal } \\
\text { MI/CHD death }(n=1222)\end{array}$} & \multicolumn{2}{|c|}{ Rate ratio $(95 \% \mathrm{Cl})$} \\
\hline & & & Unadjusted* & Adjusted $†$ \\
\hline Cerebrovascular disease & $1704(34.1)$ & $334(27.3)$ & $0.72(0.63$ to 0.83$)$ & $1.24(1.04$ to 1.49$)$ \\
\hline COPD & $286(5.7)$ & $137(11.2)$ & 2.04 (1.65 to 2.54$)$ & $1.56(1.22$ to 1.99$)$ \\
\hline Diabetes & $645(12.9)$ & $218(17.8)$ & 1.48 (1.25 to 1.75$)$ & $1.49(1.24$ to 1.78$)$ \\
\hline Atrial fibrillation & $294(5.9)$ & $73(6.0)$ & 0.98 (0.75 to 1.27$)$ & $1.04(0.78$ to 1.41$)$ \\
\hline
\end{tabular}

$\mathrm{BMI}=$ body mass index; $\mathrm{COPD}=$ chronic obstructive pulmonary disease.

*Adjusted for matched variables: sex, age, and calendar year.

†Adjusted for age, sex, calendar year, time to event, smoking, ischaemic heart disease (at start date), cerebrovascular disease (at start date), diabetes (at start date), COPD (at start date), atrial fibrillation (at start date), use of clopidogrel, statins, anticoagulants, nitrates, antihypertensives, oral steroids or non-steroidal anti-inflammatory drugs, and discontinuation of aspirin.

$\ddagger$ In year before index date.

§Reference group: no diagnosis of relevant morbidity. 
Table 2| Risk of non-fatal myocardial infarction (MI) or death from coronary heart disease (CHD) among recent discontinuers of low dose aspirin

\begin{tabular}{|c|c|c|c|c|}
\hline & \multirow{2}{*}{$\begin{array}{c}\text { No }(\%) \text { of controls } \\
(n=5000)\end{array}$} & \multirow{2}{*}{$\begin{array}{l}\text { No }(\%) \text { with non-fatal } \\
\text { MI/CHD death }(n=1222)\end{array}$} & \multicolumn{2}{|c|}{ Rate ratio $(95 \% \mathrm{Cl})$} \\
\hline & & & Unadjusted $^{*}$ & Adjusted $\dagger$ \\
\hline Current users & $3784(75.7)$ & $877(71.8)$ & 1.00 & 1.00 \\
\hline Recent discontinuers & $357(7.1)$ & $108(8.8)$ & $1.30(1.04$ to 1.63$)$ & $1.43(1.12$ to 1.84$)$ \\
\hline \multicolumn{5}{|l|}{ Duration of treatment: } \\
\hline$\leq 1$ year & $302(6.0)$ & $92(7.5)$ & 1.31 (1.02 to 1.67$)$ & $1.42(1.08$ to 1.85$)$ \\
\hline$\leq 30$ days & $65(1.3)$ & $23(1.9)$ & 1.51 (0.93 to 2.45$)$ & 1.45 (0.87 to 2.44 ) \\
\hline $31-365$ days & $237(4.7)$ & $69(5.6)$ & 1.25 (0.95 to 1.66$)$ & 1.41 (1.05 to 1.91$)$ \\
\hline$>1$ year & $55(1.1)$ & $16(1.3)$ & 1.26 (0.72 to 2.22$)$ & 1.48 (0.82 to 2.69$)$ \\
\hline \multicolumn{5}{|l|}{ Daily dose: } \\
\hline$\leq 75 \mathrm{mg}$ & $333(6.7)$ & $98(8.0)$ & $1.27(1.00$ to 1.61$)$ & $1.40(1.08$ to 1.81$)$ \\
\hline $75-300 \mathrm{mg}$ & $24(0.5)$ & $10(0.8)$ & 1.79 (0.85 to 3.77$)$ & 1.94 (0.89 to 4.22 ) \\
\hline \multicolumn{5}{|l|}{ Reason for discontinuation: } \\
\hline Lack of adherence & $242(4.8)$ & $75(6.1)$ & $1.32(1.01$ to 1.73$)$ & 1.54 (1.15 to 2.06 ) \\
\hline Treatment change & $39(0.8)$ & $17(1.4)$ & 1.95 (1.09 to 3.46$)$ & 1.94 (1.01 to 3.74 ) \\
\hline Safety concerns & $49(1.0)$ & $12(1.0)$ & 1.04 (0.55 to 1.97$)$ & 0.97 (0.50 to 1.91$)$ \\
\hline Use of over the counter aspirin & $27(0.5)$ & $4(0.3)$ & $0.68(0.24$ to 1.94$)$ & 0.82 (0.28 to 2.38$)$ \\
\hline \multicolumn{5}{|l|}{ Stratified by age (years) } \\
\hline No aged $<65$ & 1242 & 286 & - & - \\
\hline Recent discontinuers & $91(7.3)$ & $28(9.8)$ & $1.37(0.87$ to 2.15$)$ & 1.73 (1.04 to 2.87 ) \\
\hline No aged $65-74$ & 1751 & 393 & - & - \\
\hline Recent discontinuers & $127(7.3)$ & $33(8.4)$ & 1.23 (0.82 to 1.85$)$ & 1.32 (0.84 to 2.05 ) \\
\hline No aged $\geq 75$ & 2007 & 543 & - & - \\
\hline Recent discontinuers & $139(6.9)$ & $47(8.7)$ & 1.32 (0.93 to 1.87$)$ & 1.39 (0.95 to 2.05$)$ \\
\hline \multicolumn{5}{|l|}{ Stratified by sex } \\
\hline No of men & 3198 & 810 & - & - \\
\hline Recent discontinuers & $225(7.0)$ & $68(8.4)$ & 1.25 (0.94 to 1.67$)$ & 1.28 (0.94 to 1.76$)$ \\
\hline No of women & 1802 & 412 & - & - \\
\hline Recent discontinuers & $132(7.3)$ & $40(9.7)$ & $1.38(0.95$ to 2.01$)$ & 1.71 (1.13 to 2.58$)$ \\
\hline
\end{tabular}

*Adjusted for matched variables: sex, age, and calendar year.

†Adjusted for age, sex, calendar year, time to event, smoking status, ischaemic heart disease (at start date), cerebrovascular disease (at start date), diabetes (at start date), chronic obstructive pulmonary disease (at start date), and use of clopidogrel, statins, anticoagulants, nitrates, antihypertensives, oral steroids, or non-steroidal anti-inflammatory drugs. 


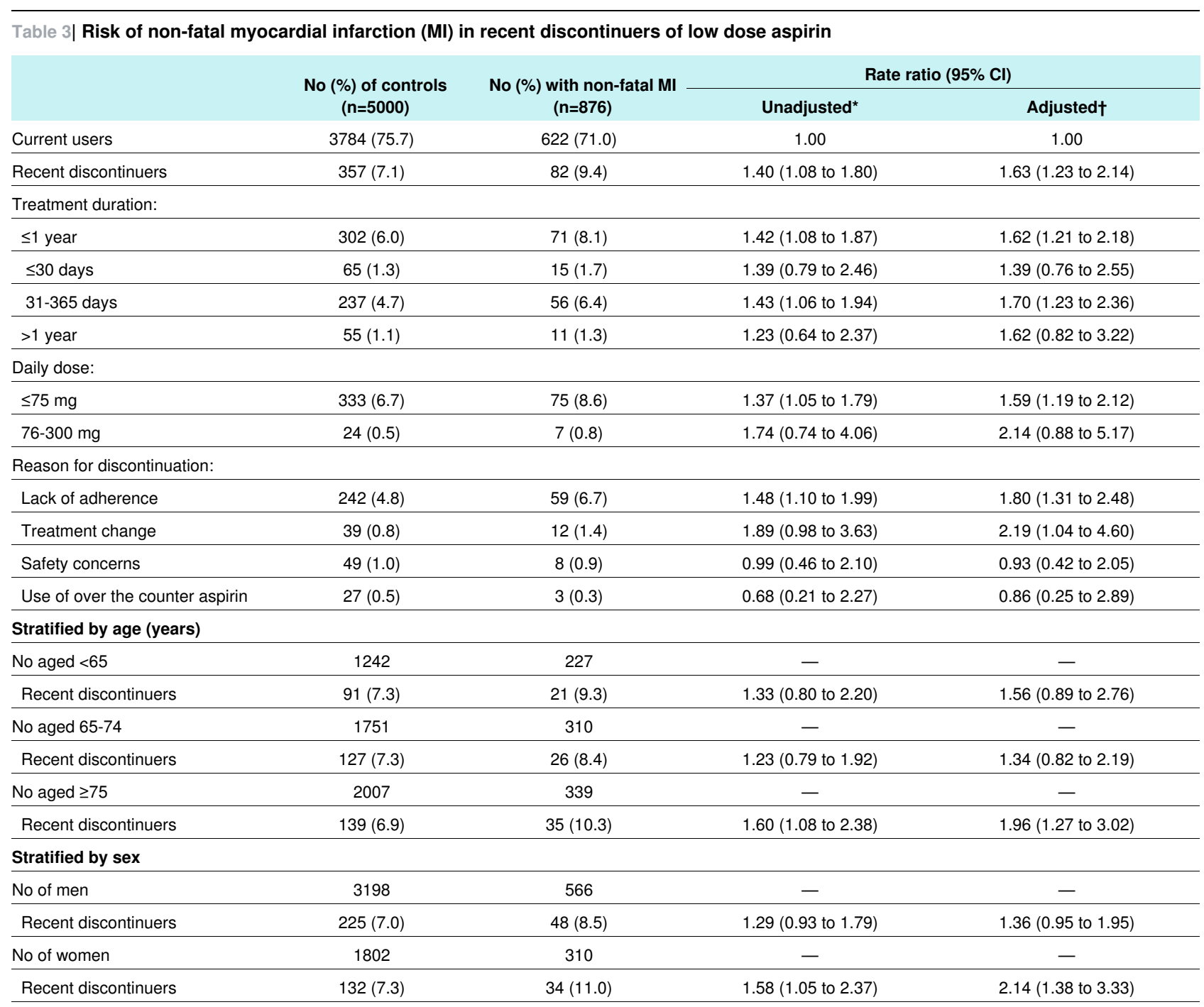

*Adjusted for matched variables: sex, age, and calendar year.

†Adjusted for age, sex, calendar year, time to event, smoking status, ischaemic heart disease (at start date), cerebrovascular disease (at start date), diabetes (at start date), chronic obstructive pulmonary disease (at start date), and use of clopidogrel, statins, anticoagulants, nitrates, antihypertensives, oral steroids, or non-steroidal anti-inflammatory drugs. 


\section{Figure}

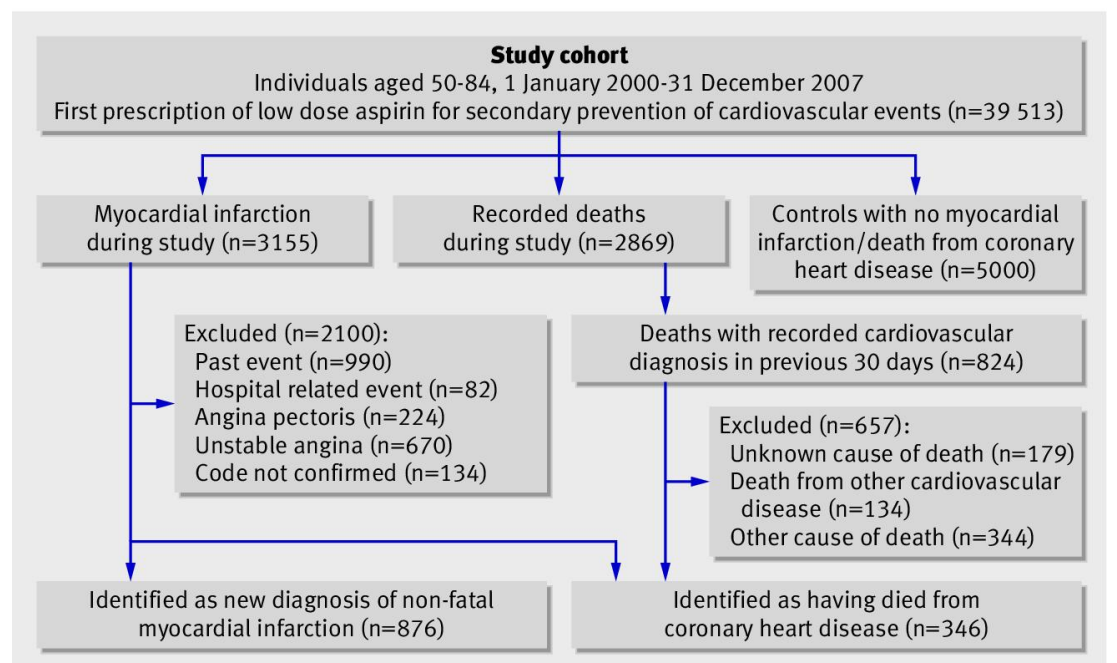

Study design and case ascertainment of non-fatal myocardial infarction and death from coronary heart disease among people prescribed aspirin in primary care 